\title{
Quiste de Nuck: no tan raro como pensamos
}

\author{
Nuck cyst: not as rare as we think
}

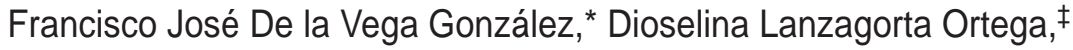 \\ Luis Jorge Fernández López, ${ }^{*}$ Jorge Santín Rivero*
}

\section{RESUMEN}

El quiste de Nuck es el equivalente del hidrocele en mujeres, ya que el tejido mesotelial que acompaña al ligamento redondo en el conducto inguinal desarrolla una colección líquida serosa, la cual dilata esta estructura hasta mostrar clínicamente un aumento de volumen; éste se puede confundir con una hernia inguinal. El estudio diagnóstico más adecuado es el ultrasonido y, en caso de dudas, se puede recurrir a la imagen por tomografía o por resonancia magnética. La resolución es completamente quirúrgica, ya que se realiza una disección y ligadura del quiste para evitar recidivas, además, en ocasiones puede requerir de plastia inguinal, debido a la concomitancia con hernia inguinal indirecta. Se presenta un caso clínico donde la paciente acude por dolor leve y aumento de volumen paulatino. En la exploración física se establece sospecha del quiste, no por la localización, sino por la falta de reducción de la lesión inguinal sin presentar otros datos clínicos de encarcelamiento. Se presentan imágenes de ultrasonido y de la disección en cirugía. En la revisión de literatura observamos que, a pesar de ser una patología poco frecuente, se han descrito numerosos casos, sobre todo en los últimos 10 años. Se reportan casos en varios países (sin existir una tendencia genética), los cuales se manejan siempre por cirugía (algunos con técnica laparoscópica) y ninguno se ha reportado con complicaciones. Ciertamente es una patología poco frecuente en cada región, pero a causa de la gran cantidad de reportes multinacionales, se realiza este análisis con el objetivo de contrastar la información y los resultados.

Palabras clave: Quiste, congénito, canal inguinal, hernia inguinal, hidrocele.

Nivel de evidencia: IV

\begin{abstract}
Nuck's cyst is the equivalent of hydrocele in women, since the mesothelial tissue that follows the round ligament in the inguinal canal develops a serous liquid collection, which dilates this structure. Clinically shows as an increase in volume, which can be confused with a inguinal hernia. The most appropriate diagnostic study is ultrasound and in case of doubt, a CT Scan or MRI can be indicated. The resolution is completely surgical, as a dissection and ligation of the cyst is performed to prevent recurrences, in addition it may occasionally require inguinal repair due to concomitance of indirect inguinal hernia. A clinical case is presented, a patient that comes for mild pain and gradual increase in volume. On physical examination suspicion of the cyst is established, because of the lack of reduction of the inguinal lesion without presenting other clinical data of incarceration. Ultrasound images and dissection in surgery are presented. In the literature review, we observe that despite being a rare disease, several cases have been reported, especially in the last 10 years. Cases are reported in several countries (without a genetic tendency), they are always managed by surgery (some with laparoscopic technique) and none have been reported with complications. It is certainly a rare disease in each region, but with the large number of multinational reports, this analysis is performed with the aim of contrasting information and results.
\end{abstract}

Keywords: Cyst, congenital, inguinal canal, inguinal hernia, hydrocele.

Level of evidence: IV

\footnotetext{
* Cirugía General.

₹ Médico Interno de Pregrado. Tecnológico de Monterrey.
}

Centro Médico ABC Santa Fe.

Recibido para publicación: 11/09/2019.

Aceptado: 08/01/2020.
Correspondencia: Dr. Francisco José De la Vega González

Av. Carlos Graef Fernández Núm. 154 (Consultorio 114), Col. Tlaxcala, 05300, Alcaldía Cuajimalpa, Ciudad de México. Tel: (55) 516647259

E-mail: fdelavega.mx@gmail.com

Abreviatura:

QN = Quiste de Nuck. 


\section{INTRODUCCIÓN}

El quiste de Nuck fue descrito por primera vez por Anton Nuck en 1692; es una patología congénita poco frecuente que aparece en mujeres jóvenes, debido a la obliteración incompleta del proceso vaginal (extensión del peritoneo parietal) que acompaña al ligamento redondo dentro del canal inguinal desde la base de las trompas de Falopio hasta el labio mayor. ${ }^{1}$

El desequilibrio entre la secreción y la absorción de líquido producido por el revestimiento mesotelial puede evolucionar, lo que origina un quiste en dicho conducto, el cual se denomina hidrocele del canal de Nuck. ${ }^{2}$ La etiología de dicha identidad es idiopática, sin embargo, puede resultar con base en el trauma o disminución en el drenaje linfático. ${ }^{3}$ Se manifiesta clínicamente como un aumento de volumen a nivel inguinal, pero si se localiza hacia la sínfisis del pubis puede producir un aumento de volumen en el labio mayor y así simular otras patologías.

El manejo en todos los casos ha sido quirúrgico, ya que se realiza resección de la lesión quística en el conducto inguinal, y en forma concomitante, una plastia inguinal, tanto por la dilatación del orificio inguinal profundo como por la presencia frecuente de hernia inguinal indirecta. ${ }^{1}$ No se han reportado complicaciones asociadas a este procedimiento.

Hasta este punto parece una patología benigna sencilla, pero como se verá más adelante en la discusión, también puede tornarse como un reto diagnóstico y de manejo si no se tiene en mente este diferencial. ${ }^{4}$ Se comentarán algunos casos en los que el quiste condiciona no sólo un defecto anatómico, sino un sitio atípico donde se presentan otras patologías. ${ }^{5,6}$

\section{CASO CLÍNICO}

Se presenta el caso de una mujer de 39 años, quien fue valorada en el consultorio por historia de molestia en la región inguinal derecha de un mes de evolución, y niega cambios de coloración o cambios en el hábito intestinal. La paciente no presenta alergias ni otros diagnósticos ni medicamentos. Tiene antecedente de cesárea, abdominoplastia y mamoplastia sin complicaciones.

En la exploración física, se palpaba un aumento de volumen en la región inguinal derecha, que no es reductible y con dolor al momento de la movilización.

Se realizó un ultrasonido inguinal en el que se evidenció dilatación quística proximal en canal inguinal (Figura 1), y se concluyó el diagnóstico de QN.
Se indicó y realizó un abordaje quirúrgico abierto (sobre sitio de abdominoplastia), explorando el conducto inguinal e identificando una lesión quística de $5 \mathrm{~cm}$, adosada al ligamento redondo, la cual se disecó y ligó distalmente para poder extirparla (Figuras 2 y 3). El análisis histopatológico reportó una lesión quística mesotelial.

Fue dada de alta de hospitalización a las 24 horas del procedimiento. Continuó con seguimiento en consulta con adecuada evolución y sin recidiva de dolor ni aumento de volumen. Finalmente, fue dada de alta posterior al mes del procedimiento.

\section{DISCUSIÓN}

En este trabajo se hizo una búsqueda del término "Nuck cyst» en PubMed, obteniendo 52 resultados. Siete de éstos son publicaciones antes del año 2000 (la más antigua de 1948) y diez trabajos fueron publicados entre el año 2000 y 2009. El restante (35 publicaciones) corresponde a casos clínicos y revisiones de la patología «quiste de Nuck»; la mayoría de los trabajos siguen el mismo formato: introducción sobre la historia del epónimo, la revisión de la

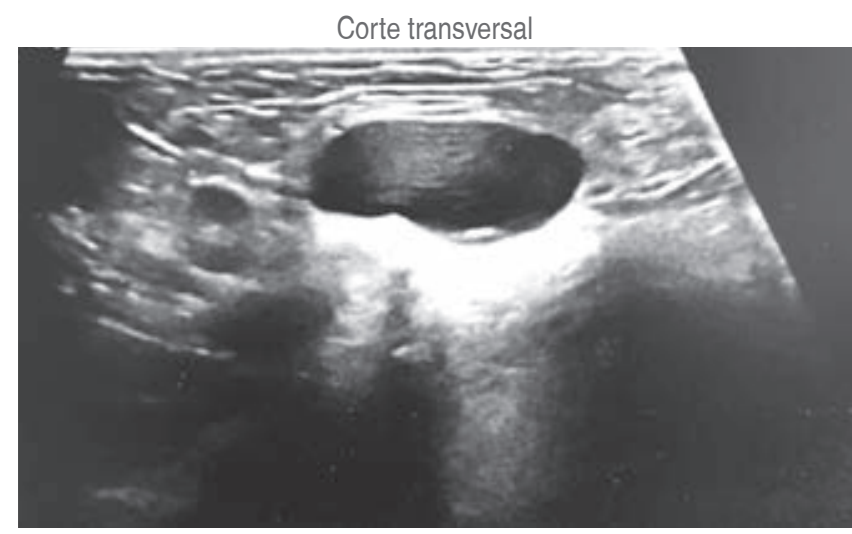

Corte longitudinal

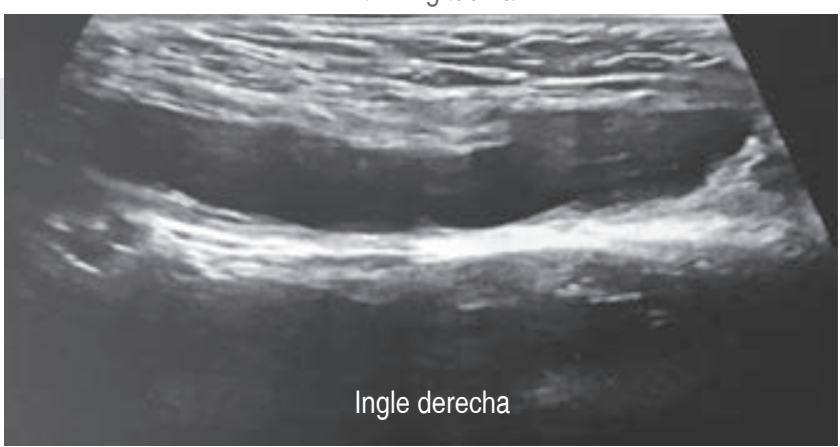

Figura 1: Ultrasonido inguinal. Corte transversal y longitudinal. 
fisiopatología, el cuadro clínico, se expone el caso y se discute acerca del reto diagnóstico que representa cuando no se tiene en mente. También hay publicaciones muy interesantes en las que el caso no sólo debuta como un aumento de volumen en la región inguinal, sino que se diagnostica como parte de un abordaje por dolor severo, esperando encontrar una hernia complicada, pero se termina por encontrar un $\mathrm{QN}$ con focos de endometriosis ${ }^{5}$ e incluso se ha documentado un embarazo ectópico no roto en la dilatación quística. ${ }^{6}$

Después de analizar todas las entradas, se encontró la siguiente información: se identificaron 20 distintas nacionalidades de los casos reportados. Aquellos países con mayor número de reportes de esta patología fueron, en primer lugar, Turquía (nueve casos); en segundo lugar, Italia (seis casos) y en tercer lugar empatan con cinco casos Japón, India y EUA. Esto nos demuestra que esta patología se presenta en grupos étnicos muy variados y que no hay una tendencia genética.

En 28 de estas publicaciones (53.8\%) se mencionó directamente que la resolución del quiste había sido quirúrgica, incluso en tres de esos casos se hizo con técnica laparoscópica (una de ellas con técnica extraperitoneal $)^{7} \sin$ complicaciones. No se reportaron complicaciones asociadas al procedimiento ni al padecimiento.

En cuanto a nuestro caso, realmente es uno muy típico. Una presentación súbita y leve, la cual condiciona la sospecha de una hernia inguinal, pero posterior a la exploración física; al ver que dicha lesión no reduce (y que clínicamente no se manifiesta como una hernia encarcelada) queda la sospecha de un posible QN. Se realiza estudio de ultrasonido donde se corrobora el diagnóstico y se

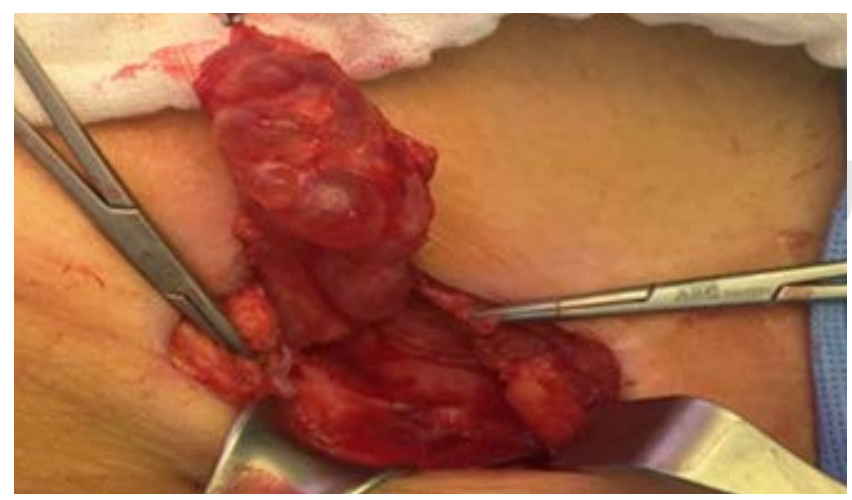

Figura 2: Lesión quística adosada al ligamento redondo en la exploración inguinal derecha. Disección y ligadura.

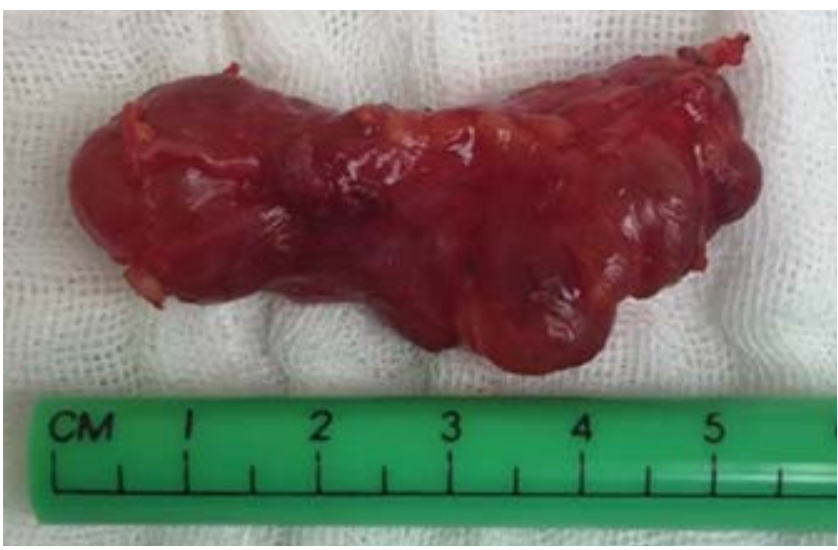

Figura 3: Pieza quirúrgica.

resuelve de forma abierta, tal como está descrito en los demás casos, además de no presentar complicaciones.

¿Qué nos queda de esta investigación? En primer lugar que, aunque su presentación es de baja frecuencia, está tan descrita esta lesión que debe estar presente en nuestros diferenciales en toda mujer con un aumento de volumen inguinal; también, que no se debe abordar quirúrgicamente sin antes realizar un ultrasonido de dicha lesión y, si queda aún así la duda, está descrito en los demás casos el uso de tomografía y resonancia magnética. ${ }^{8,9}$ No se debe olvidar que esta patología se acompaña de hernia inguinal indirecta, por lo que se debe explorar correctamente el conducto, separar ambas lesiones, ligar el quiste y tratar por separado la hernia con una plastia inguinal. El abordaje abierto o laparoscópico son igual de efectivos. ${ }^{10}$

\section{CONCLUSIÓN}

No debemos considerar al QN como una patología rara sino como una posible lesión asociada a la patología inguinal en pacientes femeninos, por lo que es recomendable realizar estudios de gabinete preoperatorios. Identificarlo correctamente permite una adecuada resección para así evitar mal diagnosticar una recidiva, sobre todo en el caso de tratamiento laparoscópico.

\section{BIBLIOGRAFÍA}

1. Jarquín-Arremilla A, García-Espinoza JA, Tafoya-Ramírez F, Lechuga-García NA. Quiste de Nuck, una entidad clínica inusual. Informe de un caso y revisión de la literatura. Cir Gen. 2018; 40 (1): 38-42. 
2. Crespí A, Lozano L, Sánchez A, Muñoz J, De la Llave A, Pallisera A et al. Quiste de Nuck en el diagnóstico diferencial de la hernia inguino-crural. Cir Esp. 2014; 92: 882.

3. Cabistany A, Martínez J, Royo B, Sanz O, Aísa G. Tumoración inguinal de etiología excepcional: quiste del canal de Nuck. Ginecol Obstet Mex. 2016; 84 (4): 265-269.

4. https://www.medigraphic.com/cgi-bin/new/resumen.cgi? IDARTICULO $=38952$

5. Noguchi D, Matsumoto N, Kamata S, Kaneko K. Embarazo ectópico con desarrollo de quiste en canal de Nuck. Obstet Gynecol. 2014; 123 (2): 472-476.

6. Okoshi K, Mizumoto M, Kinoshita K. Endometriosis asociada a hidrocele en el canal de Nuck con confirmación inmunohistoquímica: reporte de caso. J Med Case Reports. 2017; 11: 354
7. Matsumoto T, Hara T, Hirashita T, Kubo N, Hiroshige $\mathrm{S}$, Orita H. Diagnóstico laparoscópico y tratamiento de hidrocele de canal de Nuck que se extiende a espacio retroperitoneal: reporte de caso. Int J Surg Case Rep. 2014; 5: 861-864.

8. Qureshi N, Lakshman K. Excisión laparoscópica del quiste de canal de Nuck. J Min Access Surg. 2014; 10: 87-89.

9. Ozel A, Kirdar A, Halefoglu S, Erturk Z, Karpat G, Russo L et al. Quiste del canal de Nuck: hallazgos en ultrasonido y resonancia magnética. J Ultrasound. 2009; 12: 125-127.

10. Matsumoto T, Hara T, Hirashita T, Kubo N, Hiroshige S, Orita H. Diagnóstico laparoscópico y tratamiento de hidrocele del canal de Nuck que se extiende al espacio retroperitoneal: reporte de caso. Int J Surg Case Rep. 2014; 5: 861-864. 